\title{
SODIUM AND CHLORIDE DEPLETION IN ACUTE PORPHYRIA WITH REFERENCE TO THE STATUS OF ADRENAL CORTICAL FUNCTION
}

\author{
By F. T. G. PRUNTY \\ (From the Department of Chemical Pathology, St. Thomas's Hospital Medical School, \\ London, England)
}

(Received for publication December 27, 1948)

\section{INTRODUCTION}

The fact that depletion of sodium and of chloride may occur in acute porphyria, in the absence of alkalosis due to vomiting, has recently been noted independently by Abrahams, Gavey and Maclagan (1) and by Linder (2). These authors suggested that a possible basis for this deficiency was that of adrenal cortical failure, but the response of their two patients to substitution therapy with cortical hormones does not appear to have given unequivocal evidence for this hypothesis.

The present paper presents an attempt to explore this question in further detail. The plan of investigation falls under two headings: firstly to study the function of the adrenal cortex during the height of an attack of acute porphyria and secondly to observe the response to desoxycorticosterone administration in greater detail. Prunty, Forsham and Thorn (3) have recently indicated that the elucidation of adrenal cortical function with respect to its relation to electrolyte metabolism is a complex matter, whereas the functional production of the 11-oxy-steroid group of hormones is more easily assessable by urine analysis and the use of the response to purified adrenocorticotrophic hormone. The severity of the illness of the patient under observation was considered a contraindication precluding the use of the deprivation test of Cutler, Power and Wilder (4).

\section{METHODS}

The patient (Case 1) was confined to bed during the first 80 days of observation. During the period of electrolyte study she was maintained on a light diet, kept as constant as possible, with the addition of $7 \mathrm{gm}$. of sodium chloride daily, the major portion of which was given orally as half normal saline. Urine was collected daily under toluene and analysed the day of completing the collection. The methods of analysis used were as follows. Sodium by the method of Butler and Tuthill (5); chloride by the iodometric method of Van Slyke and Hiller (6) ; potassium by King's method (7); carbon dioxide combining power by the technique of Peters and Van Slyke (8). Total base in serum was estimated by electrodialysis (Malm [9]). "Neutral reducing steroids" in the urine were determined by the author's modification of the method of Talbot et al. (10), 1 and 17-ketosteroids by that of Callow, Callow and Emmens (11), using a correction equation for interfering chromogens. The adrenocorticotrophic hormone test for adrenal cortical reserve has been fully described by Forsham et al. (12). Total urine porphyrin was estimated by adsorption on a calcium phosphate precipitate followed by solution in hydrochloric acid as described by Sveinsson, Rimington and Barnes (13), the final assay of porphyrin being carried out in the fluorimeter.

\section{OBSERVATIONS}

\section{Plasma electrolyte changes}

The trend of the alterations found in the plasma electrolytes is indicated in Table $\mathrm{I}$, and Figures 1 and 2. At the commencement of the period of observation the patient was receiving potassium citrate, $2.7 \mathrm{gm}$. per diem, on account of mild urinary symptoms. At this time (15th day) there was a moderate deficiency of sodium and of chloride, the values being 125 and $86 \mathrm{MEq}$. per 1 . respectively. The carbon dioxide combining power was normal (30.4 MEq. per 1.). It will also be noted that there was a moderate elevation of blood pressure, a characteristic of this disease. On the 19th day potassium citrate was withdrawn and on the 20th day a six-day period of desoxycorticosterone acetate administration commenced. This was given in two doses per day of $5 \mathrm{mgm}$. each intramuscularly. On the fifth day of desoxycorticosterone administration the serum potassium had

\footnotetext{
1 The determination of "neutral reducing steroids" in the urine is thought to bear a relation to the endogenous 11-oxygenated corticosteroid production. The reducing substances in the urine have hitherto sometimes been loosely termed "11-oxysteroids."
} 
TABLE I

Electrolytes $M E q$ per l. serum (Case 1)

\begin{tabular}{|c|c|c|c|c|c|c|c|c|c|}
\hline Day & & $\mathrm{Na}$ & $\mathrm{K}$ & $\begin{array}{l}\text { Total } \\
\text { base }\end{array}$ & $\mathrm{CO}_{2}$ & $\mathrm{Cl}$ & Prot. & $\mathrm{Ht}$ & Urea \\
\hline $\begin{array}{l}15 \\
19 \\
20 \\
21 \\
22 \\
23 \\
24 \\
25 \\
26 \\
29 \\
33 \\
40 \\
44 \\
91 \\
97\end{array}$ & $\begin{array}{l}10 \mathrm{mgm} \text {. DOCA o.d. } \\
10 \mathrm{mgm} \text {. DOCA o.d. } \\
10 \mathrm{mgm} \text {. DOCA o.d. } \\
10 \mathrm{mgm} \text {. DOCA o.d. } \\
10 \mathrm{mgm} . \text { DOCA o.d. } \\
10 \mathrm{mgm} \text {. DOCA o.d. }\end{array}$ & $\begin{array}{l}129 \\
134 \\
133 \\
\\
\\
140\end{array}$ & $\begin{array}{l}3.5 \\
2.7 \\
1.9 \\
\\
2.1 \\
2.7 \\
2.7 \\
4.1 \\
3.5 \\
5.0\end{array}$ & $\begin{array}{l}138 \\
147 \\
145 \\
\\
145 \\
148\end{array}$ & $\begin{array}{l}30.4 \\
\\
32.5 \\
33.0 \\
32.1 \\
32.5 \\
30.0 \\
28.6\end{array}$ & $\begin{array}{r}86 \\
87 \\
\\
90 \\
\\
86 \\
87 \\
\\
89 \\
91 \\
93 \\
96 \\
101 \\
108\end{array}$ & $\begin{array}{l}5.2 \\
5.9 \\
6.4 \\
\\
6.9\end{array}$ & $\begin{array}{l}34 \\
37 \\
38\end{array}$ & $\begin{array}{c}\text { merm. } \\
\text { per cent } \\
51\end{array}$ \\
\hline
\end{tabular}

fallen as low as $1.9 \mathrm{MEq}$. per 1. There was no definite electrocardiographic evidence of potassium deficiency, but there was an increase of muscle pain suggesting the onset of the potassium deficiency syndrome, and it was decided that the desoxycorticosterone should be stopped after a further 24 hours. On cessation of desoxycorticosterone administration the serum potassium was still as low as $2.1 \mathrm{MEq}$. per 1., whereas there had only been a slight rise in serum sodium to 129 MEq. per 1. and in chloride to $89 \mathrm{MEq}$. per 1 . The behaviour of the blood pressure was unexpected in that a fall occurred from $165 / 120$ to $135 / 88$ during this period and subsequently rose again.

The patient was then maintained for ten days on sodium chloride without adjuvant therapy, during which there was slight improvement in the



Fig. 1. The Effect of Desoxycorticosterone and of Potassium on the Serum Fi.fctrolytes (CASE 1) 


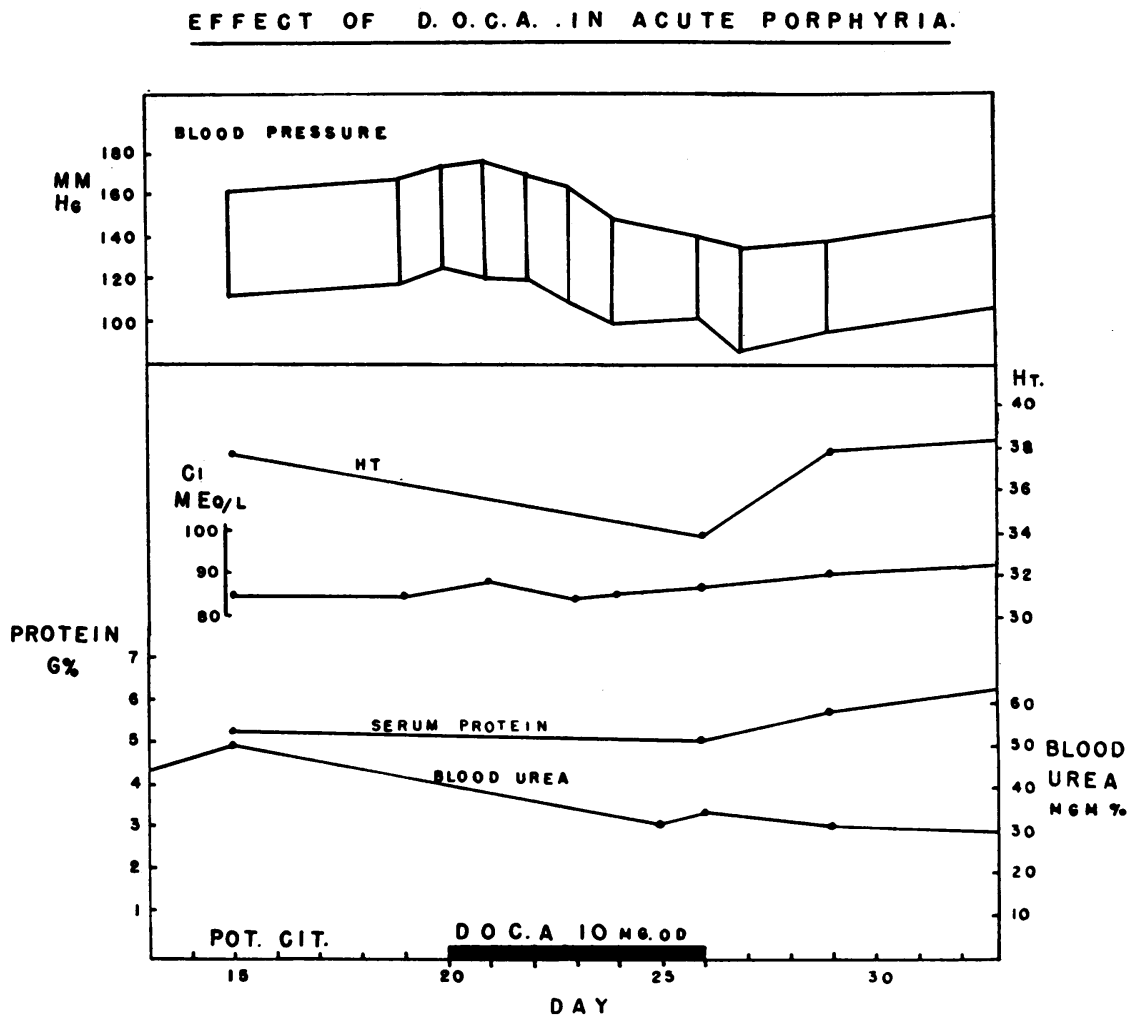

Fig. 2. The Effect of Desoxycorticosterone on Serum Chloride and Blood Pressure (CASe 1)

sodium and chloride with a persistently low potassium. Potassium chloride was given in $2 \mathrm{gm}$. doses daily from the 36th day and thereafter there was a marked improvement with respect to potassium, chloride and sodium. This corresponded to a period of clinical improvement. The changes in the carbon dioxide combining power were minimal throughout these periods.

\section{Excretion of urine chloride}

It will be seen from Table II that in spite of moderate hypochloraemia at the beginning of observation the urine chloride excretion amounted

TABLE II

Urine excretion of chloride (Case 1)

\begin{tabular}{c|c|c|c}
\hline \hline Day & DOCA & Average Cl & Urine volume \\
\cline { 2 - 4 } $18-20$ & 10 mgm. per day & MEq per day & ml. \\
$21-23$ & - & 168 & 2593 \\
$24-26$ & + & 248 & 3527 \\
$27-29$ & - & 80 & 1742 \\
$30-32$ & - & 166 & 2805 \\
& & 166 & 2687 \\
\hline
\end{tabular}

to as much as $168 \mathrm{MEq}$. per day. It remained considerable throughout the period of study.

Excretion of "neutral reducing steroids" and response to adrenocorticotrophin

On the 18th and 21st days the excretions of urinary "neutral reducing steroids" were observed to be 0.62 and $0.54 \mathrm{mgm}$. per day, about twice the normal figure. At the 90th day this excretion had fallen to normal values and there was a small fall in 17-ketosteroid excretion which remained at low normal values (Figure 3 ).

On the 16th day a single dose of $24 \mathrm{mgm}$. adrenocorticotrophin ${ }^{2}$ was given intramuscularly. This elicited after four hours a normal fall in circulating eosinophils of 91 per cent (Figure 3). The test was repeated on the 97 th day and produced a smaller decrease, amounting to 60 per cent. It should be noted that in the first case the total fasting eosinophil count was only 59 per

2 I am indebted to the Armour Laboratories, Chicago, for the adrenocorticotrophin. 
c.mm., whereas in the second case it had risen to 236 per c.mm., thus behaving inversely to the excretion of "neutral reducing steroids." The data concerning uric acid metabolism show that in the initial test the uric acid excretion was high, the fasting uric acid/creatinine ratio being 0.71 . In the second test the excretion had fallen to normal, the ratio being 0.46 . On the first occasion the response in urinary excretion of uric acid to adrenocorticotrophin was small, but this was offset by a sharp rise of 17 per cent in the plasma uric acid level. These events occurred at a time when the blood urea was elevated to $51 \mathrm{mgm}$. per $100 \mathrm{ml}$. On the second occasion the response of urine uric acid excretion was on the low side of normal, the urine uric acid/creatinine ratio rising from 0.46 to 0.69 after adrenocorticotrophin. In this test the alteration in plasma uric acid was minimal.
The interpretation of these changes would appear to be as follows (Forsham et al. [12]).

1. In the early period there was increased adrenocortical activity suggested by:

(a) Increased excretion of "neutral reducing steroids" in the urine.

(b) High fasting urine uric acid/creatinine ratio.

(c) Low fasting eosinophil count.

2. In the early period there was adequate adrenal cortical reserve function, shown by:

(a) Normal fall in eosinophil count after adrenocorticotrophin.

(b) A sharp rise in the plasma uric acid level, associated with evidence of decreased renal function and absence of increase in urine uric acid excretion at a time when uric acid excretion was already enhanced.

3. In the later period, after complete subsidence

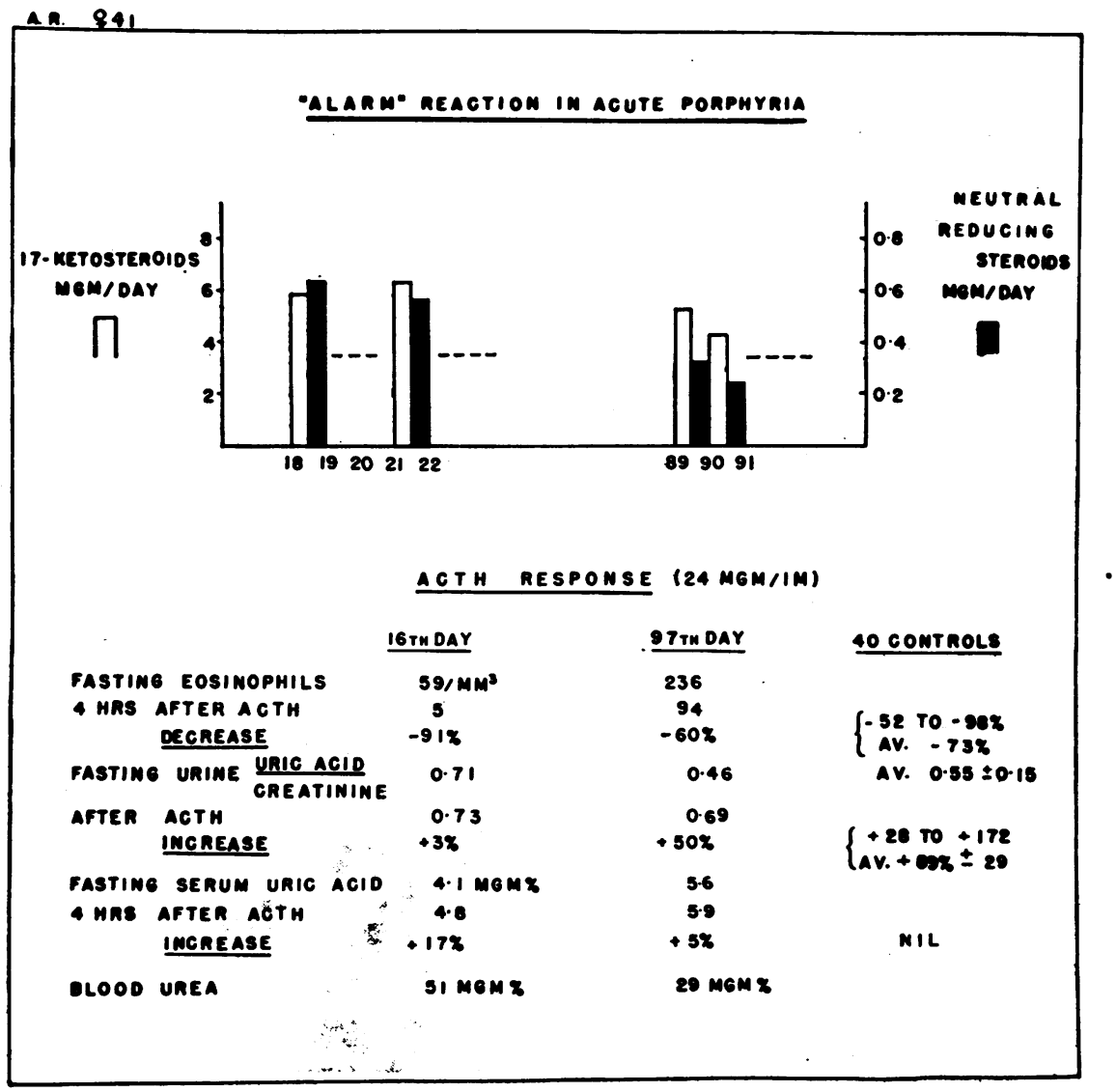

Fig. 3. "Neutral Reducing Steroid" Excretion and Resionse to Adrenocorticotrophin (CASE 1) 


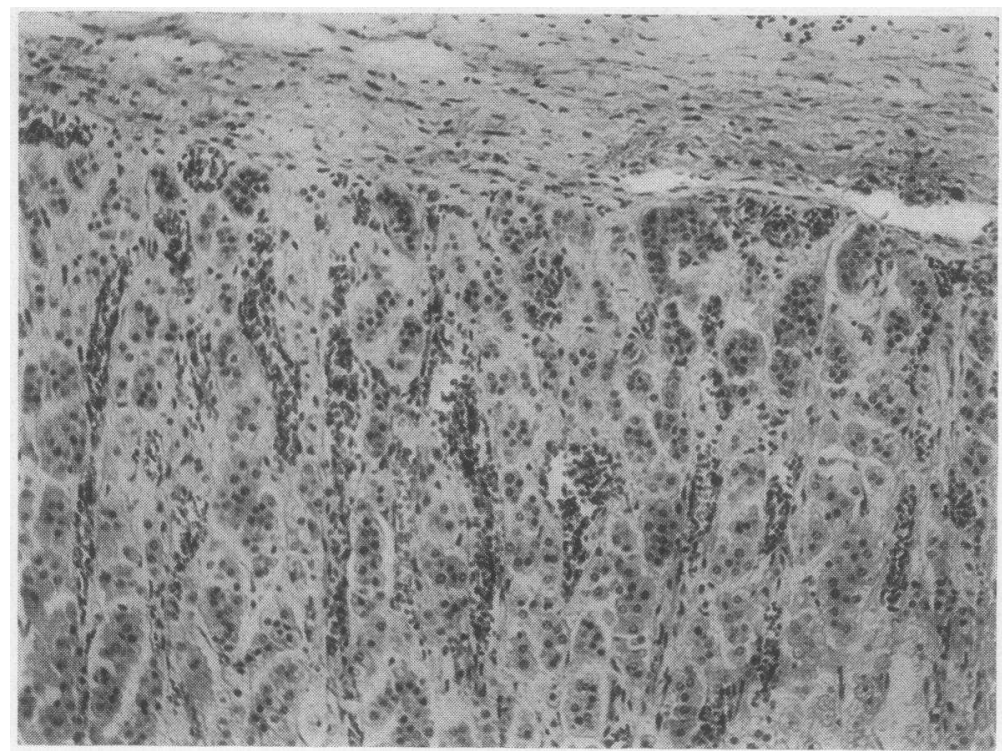

Fig. 4. Adrenal Cortex (Case 3) $\times 180$

of the attack of porphyria. the adrenal cortical activity had returned to normal, indicated by:

(a) The normal excretion of "neutral reducing steroids."

(b) The fall to normal of the fasting urine uric acid/creatinine ratio.

(c) The increase in the fasting eosinophil count.

4. In the later period there was still an adequate reserve in adrenal cortical function, shown by :

(a) Normal fall in eosinophil count after adrenocorticotrophin.

(b) Low normal response in the urine uric acid/creatinine ratio to adrenocorticotrophin.

\section{Postmortem findings in the adrenals in Cases 2 and 3}

Examination of the adrenals from two further cases of acute porphyria (Cases 2 and 3 ) gave evidence of cortical hypertrophy. In Case 2 the left adrenal weighed $7 \mathrm{gm}$. and in Case 3 the total weight of both adrenals was $16 \mathrm{gm}$. Histological examination of sections stained with haematoxylin and eosin showed hypertrophy of the cortical tissue, and the cortical widths in Cases 2 and 3 were approximately 2 and $4 \mathrm{~mm}$., respectively. In addition a greater number of cortical cells, especially in the fasciculata, showed a wellstained uniform cytoplasm and absence of lipoid vacuolation of the cytoplasm than is seen in the normal cortex (Figure 4). There is also evidence of increased capillary dilatation in these areas.

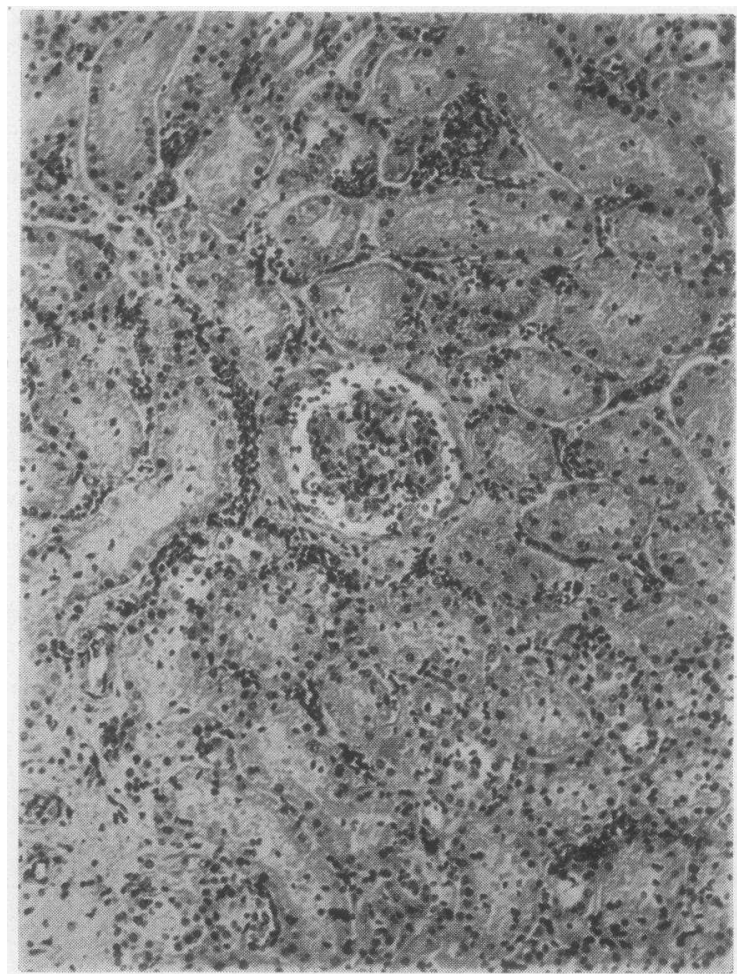

Fig. 5. Kidney, Haematoxylin and Eosin $\times 150$ (CASE 4) 
Postmortem findings in the kidneys in cases of acute porphyria

Histological examination of the kidneys from Cases 2, 3 and 4 showed similar appearances. There was congestion of the capillaries and Cases 2 and 3 particularly showed some swelling of the capsular epithelium with the presence of eosinophilic material within the capsular space (Figure $5)$. The convoluted tubules and particularly the second convoluted tubules, showed severe cloudy swelling and atrophic changes in places. The lumina of some of the tubules contained epithelial debris. The nuclei showed varying degrees of pyknosis which in places was marked (Figure 6, Case 3).

Ultraviolet microscopy of the material from Case 2 showed a ring of red fluorescence in many of the tubules and a diffuse reddish fluorescence among necrotic epithelial elements contained within the tubules. In Case 4 there was a fairly intense red fluorescence in the convoluted tubule cells and in the debris within the tubules.

\section{DISCUSSION}

The responses of fall in eosinophils and of increased uric acid excretion to adrenocorticotrophin have been shown by Forsham et al. (12) to be due primarily to 11-oxy-steroid secretion by an adrenal cortex capable of stimulation. By these criteria Case 1 would appear to have an adequate adrenal cortical reserve, both during the height of the attack of porphyria and after its cessation. The increased excretion of "neutral reducing steroids" in the urine during the acute phase is suggestive of increased adrenal cortical activity and is supported by finding some elevation of the fasting blood sugar at the conclusion of the adrenocorticotrophin test. Such a response to the adrenal is typical of the "alarm reaction" of Selye (14) to non-specific somatic trauma, and may occur in the course of any acute episode in a disease process.

The question of a parallel increase of desoxycorticosterone-like activity on the part of the adrenal under such conditions is not settled, but it is probable that the part played by the adrenal in the "alarm reaction" is mediated through the anterior pituitary (Selye [14], Long [15]) and there is evidence suggesting that anterior pitui-

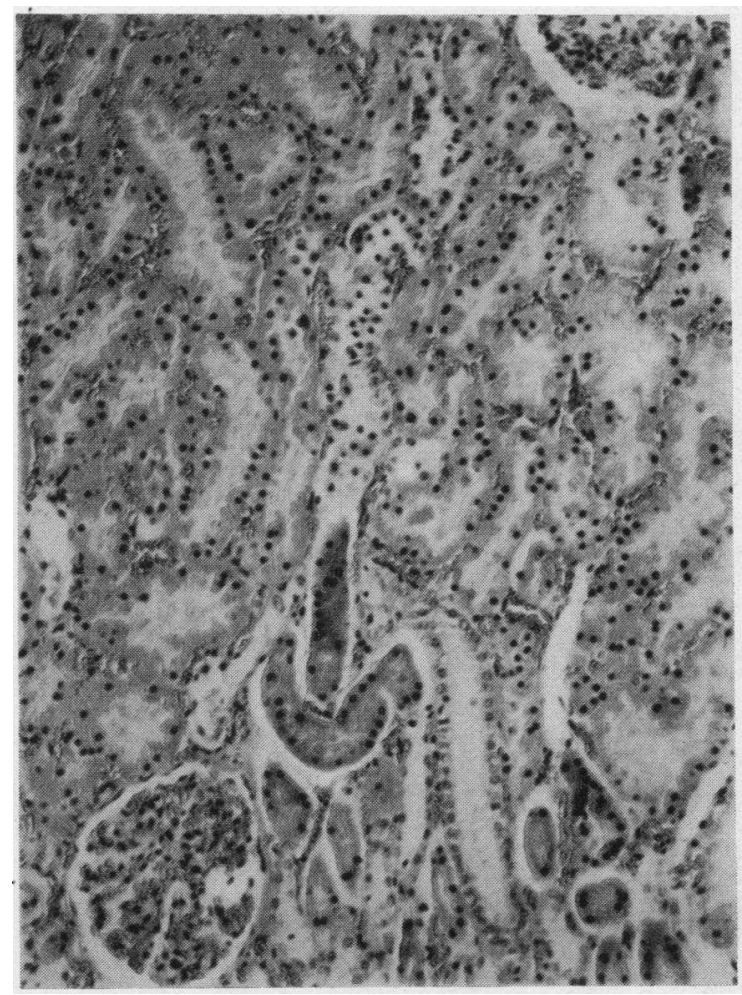

Fig. 6. Kinney, Haematoxylin and Eosin (Case 3)

tary adrenocorticotrophin can under certain conditions stimulate increased desoxycorticosteronelike activity (Prunty et al. [3]). The response of Case 1 to desoxycorticosterone was investigated with the idea that if endogenous desoxycorticosterone deficiency existed a dramatic response should be obtained as observed by Loeb et al. (16) and by Thorn et al. (17) in Addison's disease. On the other hand, if endogenous production was adequate the response would be less dramatic. The observed response was poor especially when the potentiating effect of potassium withdrawal is also considered. The most marked effect appears to have been in decreasing an already low serum potassium, which latter in itself is unlikely in the presence of endogenous deficiency of desoxycorticosterone. In the case reported by Abrahams et al. (1) the serum potassium was also below, rather than above, normal. The observation of a fall in blood pressure during the administration of desoxycorticosterone is an unusual one, and not a typical response. The effect of desoxycorticosterone in increasing chloride excretion has so far only been observed in 


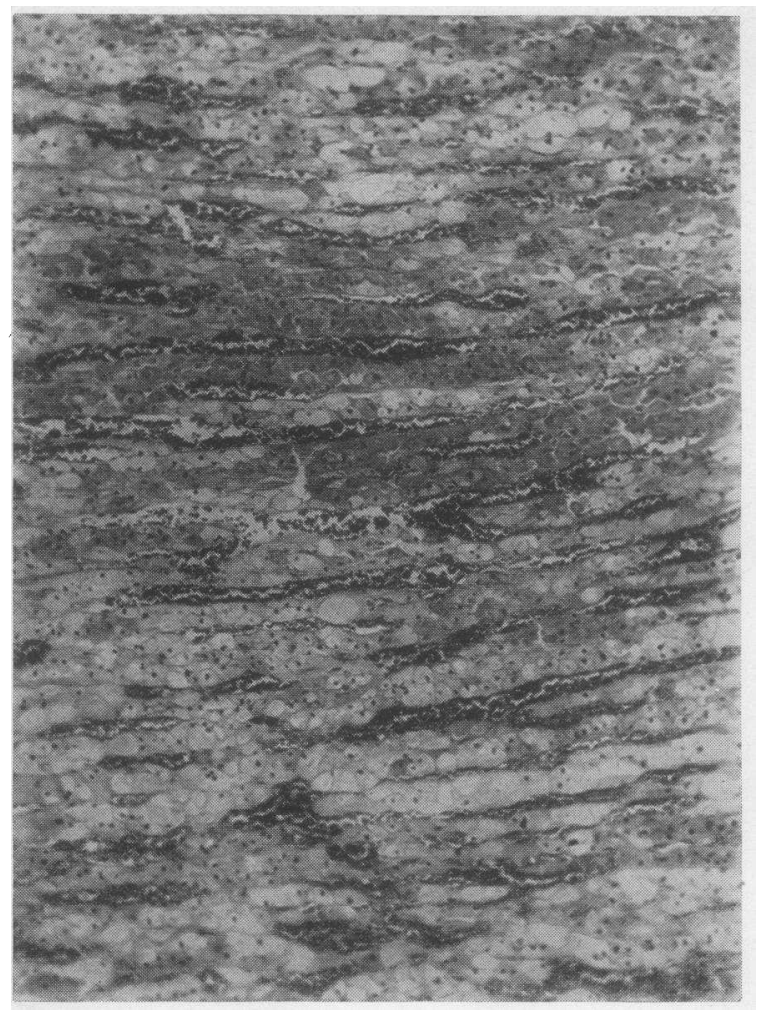

Fig. 7. Adrenal Cortex from a Case of Cushing's Syndrome, Excreting 8.2 mgm. of "Neutral Reducing Steroids" Per Diem (For Comparison)

man under conditions where available desoxycorticosterone is excessive, either from excessive administration (Zierler and Lilienthal [18]) or in Cushing's syndrome (Soffer et al. [19]). It was also found that improvement in the state of serum electrolytes and of the patient's general condition continued and even became more marked when potassium chloride was subsequently given.

The postmortem state of the adrenals in Case 2 and Case 3 suggests increased adrenal cortical activity. Adrenal hypertrophy also appears to have been present in the case of Abrahams et al. (1). The adrenals of these cases may be compared with the adrenal cortex from a man with Cushing's syndrome excretion up to $8.2 \mathrm{mgm}$. per day of "neutral reducing steroids" (Figure 7). The findings in these glands, in the light of evidence of increased cortical activity in Case 1, are compatible with those of Rogers and Williams (20).

If the sodium and chloride deficiency observed is not due to adrenal failure, some other explana- tion must be sought. Examination of the kidneys from Cases 2, 3 and 4 shows mild changes reminiscent of those seen in the so-called "renal anoxia" syndrome described by Maegraith, Havard and Parsons (21), or perhaps better termed "lower nephron nephrosis" by Lucké (22). The renal changes have been well described by Darmady et al. (23). In this syndrome failure by the kidney to retain chloride has been found to occur by Humphrey and Jones (24), and even potassium deficiency can apparently occur (Bywaters and Stead [25]). It has been shown by Thorn, Koepf and Clinton (26) that sodium and chloride retention is not induced by desoxycorticosterone when certain types of renal lesion are present, and where marked depletion of these ions may be found (Peters, Wakeman and Lee [27]). A mild degree of non-protein nitrogen retention also frequently occurs in porphyria and was observed in Cases 1,2 and 4. The possibility that the renal tubules in Case 1 may have been involved in pyelonephritic lesions must be also taken into account. Pyelonephritis was observed to occur in the case of Abrahams et al. (1). It is clear that further investigations of these points are required with more attention to the functional renal pathology.

\section{SUMMARY}

1. A phase of decreased plasma sodium and chloride has been studied in acute porphyria. This reacted poorly to administration of desoxycorticosterone acetate.

2. Data concerning the esosinophil counts, uric acid excretion and "neutral reducing steroids" excretion indicated increased adrenal activity during the acute phase of the disease. The response by the adrenal to adrenocorticotrophin stimulation showed an adequate adrenal cortical reserve function during the acute phase and in convalescence.

3. From examination of adrenals of cases of acute porphyria it is evident that cortical hypertrophy can occur and there is histological evidence that secretory activity may be increased.

4. In the light of present knowledge the correlation of the various phases of adrenal cortical activity are discussed and it is concluded that the disordered electrolyte metabolism is not primarily adrenal in origin. Abnormalities present in histological section of the kidneys suggest the 
necessity for further investigation of renal function in this disease.

\section{APPENDIX}

\section{Case notes}

Case 1. A 42-year-old woman complained that for nine days she had suffered from anorexia and nausea. She was an orphan, and had two healthy children. Since an operation for prolapse eight years previously she had had attacks of cystitis. For a week there had been marked asthenia and several attacks of vomiting with small quantities of vomitus, and she complained of an acheing pain in the lower abdomen. The attack coincided with one of her menstrual periods which were normal. She had noticed nocturia. The patient was a dark-haired individual with some generalised increased pigmentation and mild facial hirsutes. There was marked tenderness in both inguinal fossae, but no guarding, and constipation was severe. Blood pressure was 150/90, pulse rate 100 and temperature ranging up to $99^{\circ} \mathrm{F}$. The urine contained a trace of albumin and a few pus cells of which 80 per cent were polymorphs. The blood urea was $44 \mathrm{mgm}$. per $100 \mathrm{ml}$. She was given potassium citrate on account of her urinary symptoms.

After seven days penicillin therapy was commenced but without effect. After 13 days of increased pain and developing rigidity in the lower abdomen exploratory laparatomy was carried out without significant findings. The patient had become mentally poorly co-operative and was slightly hallucinated.

Her urine then was shown to contain porphobilinogen and uroporphyrin and the diagnosis of acute porphyria was established, the uroporphyrin excretion ranging from 12 to $35 \mathrm{mgm}$. per day. (A study of the porphyrin excretion is being fully reported elsewhere [McSwiney, Nicholas and Prunty, 1949] [28].)

On the 15th day her blood pressure had risen to $160 / 115$ and the pulse rate varied between 120 and 130 for the following three weeks. The plasma protein was $5.4 \mathrm{gm}$. per cent, albumin $3.3 \mathrm{gm}$. per cent, globulin plus fibrinogen $2.1 \mathrm{gm}$. per cent. Serum cholesterol was $222 \mathrm{mgm}$. per cent with 68 per cent ester; alkaline phosphatase 2.4 units, thymol turbidity 4 units; blood urea $51 \mathrm{mgm}$. per cent and icteric index 4 units. On the 16th day the urobilinogen excretion was $2.9 \mathrm{mgm}$. per day, and 10.4 mgm. per day on the 28th day. It fell to less than 1 mgm. per day from the 22 nd day onwards. At the conclusion of the adrenocorticotrophin test on the 16th day and after 18 hours' fast, the blood sugar was $131 \mathrm{mgm}$. per cent, but glycosuria was never found. Values for serum electrolytes are recorded in Table I.

Potassium citrate was withdrawn on the 18th day and desoxycorticosterone acetate $5 \mathrm{mgm}$. b.d. given intramuscularly from the 20th to 25th days inclusive, and she was receiving $7 \mathrm{gm}$. of added sodium chloride. At the end of this period of six days she complained of increasing widespread muscle pain and a constrictive feeling in the chest. There was a generalised fine somatic tremor. The electrocardiogram was interpreted as being within normal limits on two occasions, but reading was difficult on account of the tremor. Since the patient's condition had apparently deteriorated and the potassium level was so low (Table I) D.O.C.A. was withdrawn.

On the 29th day the plasma protein was $5.9 \mathrm{gm}$. per cent, albumin $3.0 \mathrm{gm}$. per cent; serum cholesterol 311 mgm. per cent, 64 per cent being ester; alkaline phosphatase 2 units; icteric index 5 units. There was a $B$. coli bacilluria which failed to improve with penicillin therapy.

On the 36th day she was given potassium chloride 2 $\mathrm{gm}$. daily in addition to the sodium chloride. From this time she started to improve clinically and the pulse rate gradually returned to normal in the following five weeks. At the end of this period she had greatly improved, the blood pressure had fallen to $130 / 60$, and urea clearance was 75 per cent of normal. The $B$. coli bacilluria was cleared up with mandelate therapy. After a further four weeks she was discharged well.

Case 2. A girl aged 16 was admitted to hospital with convulsions after a week's acute abdominal pain. Pulse rate was 110 , temperature $100.5^{\circ}$ and blood pressure $120 / 80$. Blood urea was $43 \mathrm{mgm}$. per cent, plasma protein $7.5 \mathrm{gm}$. per cent, albumin $3.4 \mathrm{gm}$. per cent. Urine urobilinogen two plus. The urine contained porphobilinogen, and uroporphyrin amounting to $15 \mathrm{mgm}$. per day. The attack subsided in three weeks.

Six months later the patient returned with abdominal pain, soon after the onset of which menstruation commenced. After two weeks ascending paralysis appeared and the patient ultimately died of bronchopneumonia and intercostal paralysis. Investigations during the attack showed 26,000 white cells; blood urea $62 \mathrm{mgm}$. per cent, plasma protein $6.5 \mathrm{gm}$. per cent, albumin $3.2 \mathrm{gm}$. per cent. There was a slight increase of urine urobilinogen and an occasional granular cast. The urine uroporphyrin excretion ranged up to $68 \mathrm{mgm}$. per day.

The chief postmortem findings were areas of focal necrosis in the liver which was shown to contain uroporphyrin by ultraviolet microscopy and analysis. It also contained porphobilinogen. The renal and adrenal findings are described above. Detailed investigations of the case have already been reported. (Prunty [29].)

Case 3. A man aged 20 complained of marked asthenia for several weeks. Six months previously he had an attack of paralysis accompanied by a dark urine, and three months previously an attack of abdominal pain with similar urine.

During the present attack the pain was generalised with tenderness in the iliac fossae. There was slight conjunctival icterus. After the onset of mild paralytic symptoms he died suddenly in ten days. The serum sodium was $126 \mathrm{MEq}$. per 1. and blood urea $34 \mathrm{mgm}$. per cent nine days before he died. Porphobilinogen and porphobilin were present in the specimen of urine examined and a moderate amount of uroporphyrin as the zinc metal complex.

At autopsy the myocardium was found to be thin, but otherwise normal. The liver showed areas suggestive of early focal necrosis. The hepatic cells contained numerous brownish pigment granules, particularly in the cen- 
tral portion of the lobules. The adrenals and kidneys have been described above.

Case 4. A man aged 26 for two months noticed a darkening in the colour of his urine. At birth a meningocele was present. He was admitted to hospital with a diagnosis of intestinal obstruction for two days. Constipation was complete. He was in shock with a very low blood pressure, pulse 140 , and temperature $101^{\circ} \mathrm{F}$. The blood contained 18,500 white cells; N.P.N. 66 mgm. per cent, carbon dioxide combining power $41 \mathrm{MEq}$. per 1., chloride $88 \mathrm{MEq}$. per 1 . The urine had a specific gravity of 1020, no albumin, but hyaline casts and unidentified brown crystals were present. There was a great deal of porphobilin present in the specimen of urine examined, with much porphyrin metal complex which could not be further identified with the amount of material available. There was a two plus reaction for urobilinogen.

The patient died at the end of a week and autopsy showed congenital absence of the left kidney with double renal pelvis and ureter on the right. There was extreme gut distention and much fluid present. The liver appeared normal. Histologically the liver showed the presence of numerous non-iron staining brownish granules in the liver cells. Ultraviolet microscopy revealed intense red fluorescence in these areas. The pigment appeared to be concentrated particularly in the cells in the central portions of the lobules, particularly about the central vein. The parenchyma in the centres of some of the lobules showed early degenerative changes. The kidney is commented upon in the text above.

I am indebted to Drs. Adams and Harewood Little for material from Cases 3 and 4.

\section{BIBLIOGRAPHY}

1. Abrahams, A., Gavey, C. J., and Maclagan, N. F., A fatal case of acute porphyria with unusual features. Brit. M. J., 1947, 2, 327.

2. Linder, G. C., Salt metabolism in acute porphyria. Lancet, 1947, 2, 649.

3. Prunty, F. T. G., Forsham, P. H., and Thorn, G. W., Desoxycorticosterone-like activity induced by adrenocorticotrophin in man. Clin. Sci., 1948, 7, 109.

4. Cutler, H. H., Power, M. H., and Wilder, R. M., Concentrations of chloride, sodium and potassium in urine and blood; their diagnostic significance in adrenal insufficiency. J. A. M. A., 1938, 111, 117.

5. Butler, A. M., and Tuthill, E., An application of the uranyl zinc acetate method for determination of sodium in biological material. J. Biol. Chem., 1931, 93, 171.

6. Van Slyke, D. D., and Hiller, A., Application of Sendroy's iodometric chloride titration to proteincontaining fluids. J. Biol. Chem., 1947, 167, 107.

7. King, E. J., Haslewood, G. A. D., Delory, G. E., and Beall, D., Microchemical methods of blood analysis, revised and extended. Lancet, 1942, 2, 207.

8. Peters, J. P., and Van Slyke, D.D., Quantitative Clinical Chemistry. Williams \& Wilkins Co., Baltimore, 1932, Vol. II, p. 245.
9. Malm, O. J., Personal communication, 1947.

10. Talbot, N. B., Saltzman, A. H., Wixom, R. L., and Wolfe, J. K., Colorimetric assay of urinary corticosteroid-like substances. J. Biol. Chem., 1945, $160,535$.

11. Callow, N. H., Callow, R. K., and Emmens, C. W., Colorimetric determination of substances containing the grouping $-\mathrm{CH}_{2} \mathrm{CO}-$ in urine extracts as indication of androgen content. Biochem. J., 1938, 32, 1312.

12. Forsham, P. H., Thorn, G. W., Prunty, F. T. G., and Hills, A. G., Clinical studies with pituitary adrenocorticotrophin. J. Clin. Endocrinol., 1948, 8, 15.

13. Sveinsson, S. L., Rimington, C., and Barnes, H. D., Complete porphyrin analysis of pathological urines. Scand. J. Clin. Biochem. \& Physiol., 1949, in press.

14. Selye, H., General adaptation syndrome and diseases of adaptation. J. Clin. Endocrinol., 1946, 6, 117.

15. Long, C. N. H., The conditions associated with the secretion of the adrenal cortex. Federation Proc., 1947, 6, 461.

16. Loeb, R. F., Atchley, D. W., Ferrebee, J. W., and Ragan, C., Observations on effect of desoxycorticosterone esters and progesterone in patients with Addison's disease. Tr. A. Am. Physicians, 1939, 54, 285.

17. Thorn, G. W., Howard, R. P., and Emerson, K., Jr., Treatment of Addison's disease with desoxycorticosterone acetate, synthetic adrenal cortical hormone (preliminary report). J: Clin. Invest., 1939, 18, 449.

18. Zierler, K. L., and Lilienthal, J. L., Jr., Sodium loss in man induced by desoxycorticosterone acetate: Study in a subject with myotonic dystrophy. Am. J. Med., 1948, 4, 186.

19. Soffer, L. J., Lesnick, G., Sorkin, S. Z., Sobotka, H. H., and Jacobs, M., Utilization of intravenously injected salt in normals and in patients with Cushing's syndrome before and after administration of desoxycorticosterone acetate. J. Clin. Invest., 1944, 23, 51.

20. Rogers, W. F., Jr., and Williams, R. H., Correlations of biochemical and histologic changes in the adrenal cortex. Arch. Path., 1947, 44, 126.

21. Maegraith, B. G., Havard, R. E., and Parsons, D. S., Renal syndrome of wide distribution induced possibly by renal anoxia. Lancet, 1945, 2, 293.

22. Lucké, B., Lower nephron nephrosis (renal lesions of crush syndrome, of burns, transfusions and other conditions affecting lower segments of nephrons). Mil. Surgeon, 1946, 99, 371.

23. Darmady, E. M., Siddons, A. H. M., Corson, T. C., Langton, C. D., Vitek, Z., Badenoch, A. W., and Scott, J. C., Traumatic uraemia. Reports on 8 cases. Lancet, 1944, $2,809$.

24. Humphrey, J. H., and Jones, F. A., Oliguria after abortion. Clin. Sc., 1947, 6, 173. 
25. Bywaters, E. G. L., and Stead, J. K., Thrombosis of the femoral artery with myohaemoglobinuria and low serum potassium concentration. Clin. Sc., 1945, 5, 195.

26. Thorn, G. W., Koepf, G. F., and Clinton, M., Jr., Renal failure simulating adrenocortical insufficiency. New England J. Med., 1944, 231, 76.

27. Peters, J. P., Wakeman, A. M., and Lee, C., Total acid-base equilibrium of plasma in health and disease; hypochloremia and total salt deficiency in nephritis. J. Clin. Invest., 1929, 6, 551.

28. McSwiney, R. R., Nicholas, R. E. H., and Prunty, F. T. G., 1949, in preparation.

29. Prunty, F. T. G., Acute porphyria; investigations on the pathology of the porphyrins and identification of the excretion of uroporphyrin I. Arch. Int. Med., 1946, 77, 623. 